\title{
RESENHA
}

Notas sobre o drama constitucional

brasileiro; resenha da defesa da Tese de

Titularidade Dialética do Poder

\section{Moderador; Ensaio de uma}

\section{Ontoteleologia do Estado do Brasil, de José Luiz Borges Horta}

Thaylor Pascoalino ${ }^{1}$

Como citar esta resenha: PASCOALINO, Thaylor. Notas sobre o drama constitucional brasileiro; resenha da defesa da Tese de Titularidade Dialética do Poder Moderador; Ensaio de uma Ontoteleologia do Estado do Brasil, de José Luiz Borges Horta. Revista de Ciências do Estado. Belo Horizonte: v. 6, n. 1, 2021, e29631. ISSN: 2525-8036.

Resenha de HORTA, José Luiz Borges Horta. Dialética do Poder Moderador; Ensaio de uma Ontoteleologia do Estado do Brasil. Belo Horizonte: Universidade Federal de Minas Gerais, 2020 (Tese, Titularidade em Teoria do Estado).

Palavras-chave: Dialética; Poder Moderador; Teoria do Estado; Hegel.

Recebido em 25.02.2021

Aprovado em 14.04.2021

Publicado em 17.04.2021

Em seu processo de avaliação para se tornar Professor Titular, o Prof. Dr. José Luiz Horta aborda um tema cuja tese — de maneira ampla, sobre a Teoria do Estado — avalia a necessidade do retorno do Poder Moderador e da construção de novos mecanismos constitucionais, por meio de uma perspectiva filosófica hegeliana. Nesse sentido, sua narrativa é estruturada em cinco etapas - ou momentos —, de intuição, Entendimento, Razão, exposição sistemática e conclusão.

\footnotetext{
${ }^{1}$ Acadêmico de Direito na Universidade Federal de Minas Gerais. E-mail: thaylorp@ufmg.br
} 
O primeiro momento é o da intuição, de que algo não estava certo. O Professor, cuja primeira década de formação se deu sob orientação do Titular a quem acabaria sucedendo (o reconhecido constitucionalista José Alfredo de Oliveira Baracho), expõe que há uma dificuldade em inovar, de forma efetiva, a estrutura de poder do Estado - com a construção de alternativas institucionais —, o que se mostra um problema decorrente de uma extrema "estatofobia". Portanto, a Teoria do Estado necessita reformular-se a fim de se adequar e atender de forma plena ao tempo presente.

Posteriormente, vem o momento do Entendimento, que visa construir uma ideia e obter materiais para a defesa da tese com base científica. $\mathrm{O}$ autor entende que a dificuldade supracitada - de se inovar na estrutura de poder do Estado — só poderia ser vencida com uma pesquisa de caráter histórico, uma vez que, para ele, o Estado tem uma historicidade que deve ser ressaltada; sem essa dimensão histórica não é possível compreender o Direito. É muito clara e evidente a base culturalista que alicerça as concepções jurídicas do Professor Horta. Com efeito, conclui que existe um desmonte da estrutura de poderes do Estado, isto é, uma ineficiência historicamente construída desta, que se concretiza em um sequestro do político e, na prática, é representada pelo vácuo do poder moderador. Todavia, mesmo com os estudos científicos, não foi possível concluir — apenas com o auxílio destes — o motivo da inadequação da teoria do Estado - que, recapitulando, se concretiza com a ausência do poder moderador - para os dias atuais. Por isso, o Professor passa ao terceiro momento, do emprego da Razão.

Agora, com a elevação do problema ao plano filosófico ${ }^{2}$, o autor faz uso da Razão por meio do estudo do Romantismo e do Idealismo alemães, presentes na filosofia hegeliana, na tentativa de propor uma tese de percepção e compreensão do Brasil e seu Estado a partir da questão do poder moderador visto sob este viés hegeliano, filosófico, dialético. É importante ressaltar que entender Hegel — ser um hegeliano, ou ao menos um bom hegelianista requer assumi-lo como um filósofo reconciliador entre Ilustração e Romantismo. Os hegelianistas, aqueles que não compreendem Hegel em sua totalidade, não estão preparados para captá-lo tal qual um conciliador, por isso sempre ignoram uma das correntes, o que dificulta o estudo preciso da Dialética construída como base do pensamento filosófico do autor.

\footnotetext{
2 A passagem ou trânsito do pensamento de Horta do plano teórico ou científico (Entendimento) ao plano filosófico (Razão) deu-se na seara aberta pelos filósofos Joaquim Carlos Salgado e Gonçal Mayos Solsona. Com Salgado, filósofo do Direito e do Estado, fundador da Escola Jusfilosófica Mineira, Horta doutorou-se e estuda Hegel há mais de quinze anos; com Mayos, filósofo da Cultura e ensaísta catalão, esteve em pós-doutorado e mantém projetos de pesquisa internacionais.
} 
A tese possui três momentos. O primeiro é o da Filosofia do Estado: momento em que se trabalham os elementos centrais para uma Filosofia do Estado adequada ao tempo presente. O segundo é sobre a Ontologia de um Estado em cisão, em que se identifica que o ser do Estado do Brasil, seu Ontos, está em permanente cisão. Por fim, tem-se a Teleologia do Estado brasileiro: quando, através da dualidade entre passado (que constitui o ser) e futuro (que constitui o devir), será possível construir alternativas de imaginação institucional ${ }^{3}$ que estejam em acordo com os elementos teleológicos que o Estado brasileiro possui. Ou seja, o autor buscará, a partir do estudo da filosofia de Hegel, compreender o Estado, sua infinita cisão e, com isso - trazer um diálogo entre diferentes tempos —, propor alternativas constitucionais adequadas ao Brasil — fato apontado como a principal dificuldade da contemporaneidade, dentro da Teoria do Estado - , que concentra no ressurgimento do Poder Moderador.

A exposição sistemática consiste em explicar o que é a Dialética do Poder Moderador, uma vez que, apenas com essa compreensão, pode-se tirar de base os motivos que levam o autor a repensar a volta de tal estrutura. Nesse sentido, faz-se obrigatório pensar a Dialética, antes de se entender a Dialética do Poder Moderador.

Hegel é um filósofo sistemático. Isto significa que seu pensamento é, de antemão, organizado e estruturado acerca da totalidade das coisas. Nada escapa à sua filosofia que, por isso, é plural e inclusiva. Com efeito, compreender a totalidade pressupõe a existência da dialética. Horta nos diz que "A totalidade somente pode ocorrer mediante processo por Hegel intitulado de Dialética" (HORTA, 2020, p. 45). Dessa forma, entendamos o que é Dialética.

Muitos, em vão, intitularam dialética como um "método" para estudar a realidade, composto por tese-antítese-síntese. Ora, essa visão jamais abarca o peso da Dialética proposta por Hegel. A Dialética é a própria realidade, pois está em constante movimento assim como esta. É algo vivo, não estático como o viés metodológico. Seria impossível caracterizar a Dialética como um método de enxergar o real, pois o real está em constante cisão e reconciliação. A ideia de método nada mais faz do que a captura de um momento e isso, por sua vez, nada mais é do que o que está escrito: a captura de um momento. Não pode - e não deve — ser tomado como o real absoluto. A Dialética é um processo composto por afirmação-negação-negação da negação. Sendo viva, a reconciliação, gerada pela negação da

\footnotetext{
${ }^{3}$ O termo cunhado por Roberto Mangabeira Unger, catedrático da Universidade de Harvard, propõe um papel ativo ao jurista, indicando que a criação de mecanismos de inovação institucional e doutrinária é obrigação do cientista do Direito e do Estado frente à tendência de sacralização do status quo, a qual entende uma posição fixa e imutável do Ordenamento. É literalmente, ter imaginação — e disposição — para promover mudanças que façam com que o Direito seja um reflexo da sociedade que o compõe, sempre mutável.
} 
negação, já abre espaço para novas cisões, uma vez que o processo é infinito, visto que nossa própria natureza, cultural ou espiritual, é dialética.

A tentativa de transformar dialética em metodologia faz com que a síntese seja uma mera justaposição entre tese e antítese. Na verdade, dialeticamente falando, tudo sofre cisão e reconciliação, não há processos separados para junção posterior. A Dialética alça, a outro plano, algo que não existia. De forma alegórica, o "método dialético" está para um processo físico, assim como a Dialética efetivamente hegeliana está para um processo alquímico. Em suma, "Abjurar a Dialética, teimando em posições filosóficas estáticas e/ou abstratas, não altera a realidade, apenas dela nos aliena" (HORTA, 2020, p. 47). Dialética é vida, trânsito, transformação permanente, movimento, tudo o que não seja inércia. Este processo sempre produz uma realidade universal e concreta ao mesmo tempo, o que prova a elevação como algo singular.

A Dialética do Poder Moderador, consoante José Luiz Horta, possui três dialéticas dentro de si. A primeira é a dialética maior, entre a afirmação do Poder Moderador no Império e a negação deste na República. Por sua vez, a segunda seria interna à afirmação do Poder Moderador no Império: afirmação, vista em Benjamin Constant; negação, em D. Pedro I; e negação da negação - reconciliação — entre estas em D. Pedro II. Por fim, vem a dialética interna à negação do Poder Moderador na República: afirmação abstrata, na República Velha (que nega o Poder Moderador), a negação dessa afirmação, que seria a República Social (que, para alguns, teria abusado do Poder Moderador), e a reconciliação, com a República "Forense", onde há uma luta pelo retorno do Poder Moderador.

Logo, chegamos às conclusões, sempre sumarizadas. Assim, o autor conclui que é o Estado uma realidade macro e que vencer a estatofobia do tempo presente exige sempre alçar o Estado ao plano filosófico, pois só assim é possível entende-lo por completo. Esse processo de elevação ao plano filosófico pressupõe a filosofia hegeliana, pois esta é basilar para a construção do que chama de uma Ontoteleologia do Estado.

O segundo grupo de conclusões é referente à Ontologia do nosso Estado em permanente cisão. Dessa forma, na concepção do Estado e da primeira Constituição brasileira, introduziu-se uma estrutura de poder desconhecida do constitucionalismo mundial, que seria o Poder Moderador, chave de compreensão da ordem constitucional imperial. Para o autor, Pedro I criou o Poder Moderador no Brasil como alternativa prática para a rápida eliminação de conflitos e a consolidação da coroa imperial. Logo, o Poder Moderador se concretizou no Brasil como chave de toda a organização política. Ao longo da história, no entanto, mesmo com seu fim legal, o Poder Moderador continuou sendo exercido de outras formas. Na Era 
Vargas, por exemplo, o Executivo hipertrofiou-se, viabilizando um real incremento de poder nas Forças Armadas que, fortalecidas, exerceram abertamente o Poder Moderador no cenário Pós-Vargas. Assim também ocorreu após o golpe em João Goulart na década de 1960 e continua ocorrendo desde a Constituição de 1988 - aqui com uma maneira diferente de afirmar o Poder Moderador —, marcada, desta vez, pelo inchaço das funções jurisdicionais que configurou o Poder Judiciário como um novo Poder Moderador.

Por fim, tem-se as conclusões acerca da Teleologia do Estado do Brasil. Recapitulando, a teleologia do Estado busca compreender o devir do Estado a partir de seus fins, de sua vocação, de sua razão de ser. Vale ressaltar que a cisão mais importante para este estudo é a primeira, visto que, com a constatação de uma dialética não resolvida, há a falta do momento de elevação. Não houve, portanto, uma reconciliação entre a afirmação do Poder Moderador no Império e sua negação na República e, aqui, reside um ponto importante do texto, já que a negação da negação — reconciliação — desta dialética é o que propõe o autor. É por meio de tal reconciliação que o Professor estuda e sugere o retorno do Poder Moderador, de forma constitucional, para adequar a Teoria do Estado a seu tempo e, com isso, inovar as estruturas de poder do Estado. A reconciliação é imperativa; sem ela não é possível o ressurgimento de tal aparato estatal.

A restauração do Poder Moderador, no entanto, exige a sua retirada das sombras da constituição real e posterior elevação a categoria democrática. Não seria possível uma simples repristinação do Poder Moderador garantido pela Constituição de 1824, já que povos desenvolvidos repactuam sua convivência em jovens constituições que representam momentos privilegiados de reconciliação nacional, isto é, não seria possível o retorno deste Poder por meio da repristinação, pois aquele modelo constitucional já não atende às demandas dos tempos atuais - além de ser um fenômeno impróprio a repristinação para os dias de hoje. Portanto, o Poder Moderador deve retornar de forma legal, por meio de sua constitucionalização democrática e, com o fito de evitar os erros do passado, sua delegação não estaria nas mãos de apenas um indivíduo - representado pelo chefe de Estado —, mas talvez de um conselho de Estado composto de membros natos. Nesse sentido, com seu ressurgimento e aceitação, a configuração mais ousada do Poder Moderador seria a "republicana ampla", na qual o Senado seria seu órgão de cúpula. A restauração do Poder Moderador é de suma importância para que se vença a estatofobia presente nos dias atuais e 
acentuada - quiçá cultivada — pelo neoliberalismo ${ }^{4}$. O brasileiro já não consegue reconhecer a Constituição de forma plena, o que é fruto da ausência da reconciliação supracitada.

Também conclui o Professor que o processo dialético de ascensão do Poder Moderador exige um comprometimento com o direito que pressupõe uma reinvenção, também, das faculdades de direito, uma vez que o ensino jurídico tem se mostrando alienante e, com isso, produzido profissionais alienados. Portanto, a educação jurídica deve ser redimensionada em todos os níveis.

Considerando que a sociedade avança de forma mais veloz que o texto constitucional — decorrente dos mecanismos burocráticos de mudanças —, compreendo como lógica a tese do Professor, que, de forma geral, é sobre um problema da Teoria do Estado — da sua não aplicação plena aos dias atuais. É notória a necessidade de adequações tanto constitucionais, quanto na Teoria do Estado para suas aplicabilidades plenas. Nesse sentido, a solução encontrada pelo Professor, que é a retomada de um Poder Moderador mais “constitucionalizado" talvez não seja o suficiente e, ao meu ver, tem alguns problemas.

Penso que o retorno do Poder Moderador - seu ressurgimento, como apontou o Professor - é algo importante e até urgente. É importante para trazer as soluções alternativas a que nosso tempo anseia - e que não têm sido encontradas - e, ao mesmo tempo, urgente, pois o que a defesa da Tese nos mostra é que, de uma forma ou de outra, o Poder Moderador já está instaurado em nossa sociedade com a hipertrofia de alguma esfera de poder, seja judiciária, executiva ou legislativa, contudo de forma inconstitucional. Ora, o ressurgimento do Poder Moderador passa, portanto, até mesmo por um processo de legitimação, ou seja, se este quarto poder já existe, melhor que exista constitucionalmente. Não é possível aceitar que tenhamos um judiciário que atue em causas inadequadas e mais, que atue buscando atender os anseios da população porque lhe foi dado um papel de protagonismo político pós-Constituição de 1988: nosso judiciário se sente superior aos cidadãos e demais poderes. Agindo o juiz como um semideus, portanto, não há limites para a sua atuação, em tese, e não só em tese. Vemos que, na prática, há cada vez mais escândalos relativos à interferência judiciária e a atuações partidárias que vaporizam a Constituição. Esse poder exercido, que extrapola os demais poderes, é de fato o Poder Moderador em uso, como o que talvez imaginasse D. Pedro

\footnotetext{
${ }^{4}$ Como dito pelo Professor Horta, o canto das sereias neoliberais trouxe ao mundo o Estado Poiético (HORTA, 2017, p. 90-1), compreendido pelo Professor Joaquim Carlos Salgado como um modelo sumariamente subjugado à perspectiva econômica - antes mesmo da jurídica, ética ou social. Esta forma de organização é a representação, em suma, da destruição do Estado de Direito - pelo menos para Salgado —, pois este deve ser, em essência, Ético. (SALGADO, 1998).
} 
I. Por isso, urge a necessidade de torná-lo legal. Somente assim tais casos poderiam ser evitados. É uma questão concreta.

A posteriori, devo ponderar que o Poder Moderador, sozinho, talvez não seja capaz de representar as mudanças necessárias para reorganizar a Teoria do Estado, já que elas devem acompanhar os anseios e ser um reflexo da sociedade atual, e esta, por sua vez, é dotada de uma volatilidade sem fim.

Foi Zygmunt Bauman (2001), filósofo e sociólogo polonês, o responsável por alertar sobre o fato: Para ele, vivemos em uma modernidade líquida e esta, assim como a propriedade física respectiva, é incerta, dotada de uma volatilidade só nossa, decorrente de uma carência de referenciais. Nada é feito para durar e o pensador se escora no amor, que agora é muito mais passageiro — a exemplo da média de duração de casamentos que caiu consideravelmente -, para refletir sobre a sociedade contemporânea, como um todo.

Portanto, temos um mundo liquefeito, onde as certezas foram desfeitas. Onde não há certezas, não há narrativas suficientes para a explicação do todo, como bem salientou Gonçal Mayos (2012, p. 9-15). Para a Macrofilosofia de Mayos (e de Horta), a perspectiva da totalidade necessária para a compreensão da realidade - e de tudo o mais que nos permeia foi, também, desconstruída ao longo do tempo por uma visão analítica. Isto faz com que tenhamos acesso à informação, mas não à verdade de fato. Mayos exemplifica essa tendência com o fato de que cada vez mais pesquisas são estruturadas no entorno de uma única obra ao invés de uma visão holística, ou, para ele, macro.

A filosofia, no mundo da fragmentação ou da liquefação, também sofre, mas se ela passa a adotar uma visão que não a de compreensão do todo, arrisca-se a igualar-se a mera ciência, deixando, portanto, de ser filosofia para, no máximo, ser uma boa filologia. Por isso, o Estado tem passado por um processo de entendimento errôneo, como bem explicado pelo Professor Horta. Somente é possível entender o Estado, que é um complexo emaranhado de acontecimentos antagônicos e históricos, fazendo-se uma filosofia do Estado em sua essência. A partir dos marcos analíticos como têm sido feitos o estudo e as tentativas de sua compreensão, o Estado é, de fato, um mistério. "Uma abordagem microfilosófica mantém o estudioso na antessala do saber", vai asseverar Horta (2020, p. 22).

Para decifrar o enigma do Estado - e dar fim ao drama constitucional brasileiro junto a este Poder Moderador, seria necessário, a meu ver, um mecanismo que entendesse a sociedade em sua volatilidade absoluta e, por meio disso, construísse uma logística de atualização do texto constitucional de forma a não ser muito veloz — para que a Constituição 
não perca seu caráter de permanência —, nem devagar o suficiente para que aquele não se torne obsoleto, algo cada vez mais comum nos tempos atuais.

Em certo sentido - já que responde bem mais do que o necessário —, há uma esfinge a ser desvendada; a questão do Estado e, sobretudo, do Estado brasileiro diante de uma nova realidade que se desenha, o Constitucionalismo estratégico (HORTA: 2012). Frente aos modelos clássico, social e democrático, esta forma de constitucionalismo enxerga o Estado como uma representação de influência - em todos os níveis - , para os que estão ao seu redor. É uma resposta ao Império cosmopolita, que, alçado pela globalização, tende a enxergar o mundo sob o aspecto de uma aldeia global comandada por um cacique ou, nos termos técnicos, uma potência hegemônica - atualmente os Estados Unidos. O projeto de constitucionalismo estratégico propugna que o Brasil tenha seu lugar de protagonismo na América (HORTA: 2012, p. 803), e também no mundo, reconhecido e — paralelamente —, como visto na tese, que o país se prepare e prepare suas instituições constitucionais para o protagonismo do devir.

\section{REFERÊNCIAS BIBLIOGRÁFICAS}

BAUMAN, Zygmunt. Modernidade Líquida. Trad. Plínio Dentzien. Rio de Janeiro: Zahar: 2001.

HORTA, José Luiz Borges. A subversão do fim da História e a falácia do fim do Estado; notas para uma Filosofia do tempo presente. In: HORTA, José Luiz Borges; SALGADO, Karine. História, Estado e Idealismo Alemão. Belo Horizonte: Editora UFMG, 2017, p. 83-96.

HORTA, José Luiz Borges. Dialética do Poder Moderador; Ensaio de uma Ontoteleologia do Estado do Brasil. Belo Horizonte: Universidade Federal de Minas
Gerais, 2020 (Tese, Titularidade em Teoria do Estado).

HORTA, José Luiz Borges. Urgência e emergência do constitucionalismo estratégico. Revista Brasileira de Estudos Constitucionais, Belo Horizonte, Fórum, a. 6, n. 2, p. 783-806, jul./set. 2012.

MAYOS, Gonçal. Macrofilosofia de la Modernidad. Rota: dLibro, 2012.

SALGADO, Joaquim Carlos. O Estado Ético e o Estado Poiético. Revista do TCE, Belo Horizonte, Tribunal de Contas do Estado de Minas Gerais, v. 27, n. 2, p. 37-68, abr./jun. 1998. 
NOTES ON BRAZILIAN CONSTITUTIONAL DRAMA; REVIEW OF THE DEFENSE OF THE HABILITATION THESIS DIALECTICS OF THE MODERATIVE POWER; ESSAY OF AN ONTOTELEOLOGY OF THE STATE OF BRAZIL, FROM JOSÉ LUIZ BORGES HORTA

Thaylor Pascoalino

How to cite this review: PASCOALINO, Thaylor. Notas sobre o drama constitucional brasileiro; resenha da defesa da Tese de Titularidade Dialética do Poder Moderador; Ensaio de uma Ontoteleologia do Estado do Brasil de José Luiz Borges Horta. Revista de Ciências do Estado. Belo Horizonte: v. 6, n. 1, 2021, e29631. ISSN: 2525-8036.

Keywords: Dialectics; Moderative Power; Theory of the State; Hegel. 